\title{
Bacterial Chromosome Organization and Segregation
}

\author{
Esteban Toro and Lucy Shapiro \\ Department of Developmental Biology, Beckman Center, Stanford University School of Medicine, \\ Stanford, California 94305 \\ Correspondence: etoro@stanford.edu
}

\begin{abstract}
Bacterial chromosomes are generally $\sim 1000$ times longer than the cells in which they reside, and concurrent replication, segregation, and transcription/translation of this crowded mass of DNA poses a challenging organizational problem. Recent advances in cell-imaging technology with subdiffraction resolution have revealed that the bacterial nucleoid is reliably oriented and highly organized within the cell. Such organization is transmitted from one generation to the next by progressive segregation of daughter chromosomes and anchoring of DNA to the cell envelope. Active segregation by a mitotic machinery appears to be common; however, the mode of chromosome segregation varies significantly from species to species.
\end{abstract}

$T_{\text {has }}^{\text {h }}$ he DNA molecule is a remarkably simple and elegant storage medium for genetic information. However, linear encoding of this kind demands an inordinately long molecule, and so, bacterial chromosomes are much longer than the cells in which they reside. For example, Caulobacter crescentus packages a $1.3 \mathrm{~mm}(4.0$ Mbp) genome in a 2 micron cell. This spatial constraint creates a daunting organizational problem that is exacerbated on DNA replication, an act that not only doubles the amount of DNA in the cell, but also creates topologically linked molecules. Watson and Crick published a companion paper to their 1953 DNA structure in which they pointed out that the elegant simplicity of the copying mechanism they proposed was complicated by the fact that the two strands wind around each other. Hence, to create two separate chromosomes, it is necessary to unlink the original two strands, which, even in the case of a bacterial genome, amounts to unwinding several hundreds of thousands of turns. They wrote: "Although it is difficult at the moment to see how these processes occur without everything getting tangled, we do not feel that this objection will be insuperable" (Watson and Crick 1953). Indeed, in 1971, James Wang purified the first of a class of proteins we now know as DNA topoisomerases (Wang 1971), which solve this particular problem by catalyzing the passage of single strands or duplexes of DNA through each other (Schoeffler and Berger 2008).

Topoisomerases thus provide a solution to the problem of DNA tangling within the cell.

Editors: Lucy Shapiro and Richard Losick

Additional Perspectives on Cell Biology of Bacteria available at www.cshperspectives.org

Copyright (C) 2010 Cold Spring Harbor Laboratory Press; all rights reserved; doi: 10.1101/cshperspect.a000349

Cite this article as Cold Spring Harb Perspect Biol 2010;2:a000349 
Other, less biochemically tractable aspects of DNA spatial organization, however, received little attention for a considerable time, partly for technical reasons, but also because bacteria were seen as the proverbial "bag of enzymes," i.e., small enough for diffusive processes to dominate and thus not requiring any spatial organization. We now know that the bacterial cell is in fact highly organized (Thanbichler and Shapiro 2008), and the chromosome is no exception.

Here, we concentrate on recent findings about the dynamic high-order organization of the bacterial chromosome; that is, how is DNA organized within the cell and how is it segregated faithfully to each daughter cell on division? Our understanding of these two questions has progressed greatly in the past few years, aided in large part by advances in imaging technologies. For the sake of clarity, we explore each question independently. However, as will be clear throughout, DNA segregation and organization are intimately linked.

\section{DNA ORGANIZATION WITHIN THE CELL}

\section{The Early Years and the Rosette Model}

The very first investigations into the structure of the bacterial nucleoid came in the form of light microscopy of stained specimens (e.g., Feulgen and Giemsa staining), and electron microscopy of thin sections (reviewed in Robinow and Kellenberger 1994). These studies showed that although the nucleoid is mostly separate from the rest of the cytoplasm, it is not bound by a nuclear membrane (Robinow 1956). Some DNA strands extrude from the nucleoid into the cytoplasm like loose pieces in an otherwise tight ball of yarn (Kellenberger 1991), and autoradiography of transcribing genes suggested that these excrescences contain most of the transcriptionally active DNA (Ryter and Chang 1975).

As important as they were, these first studies were based on only limited resolution. In 1971, Stonington and Pettijohn opened a new window by developing a method to gently lyse Escherichia coli cells in solutions of high ionic strength to isolate "folded" chromosomes, i.e., free DNA that does not increase the viscosity of the solution. These isolated chromosomes contained nearly all of the DNA present in the lysate, some protein, and all nascent RNA (Stonington and Pettijohn 1971). Depending on the conditions of isolation, chromosomes were obtained in either membrane-associated or membrane-free form (Kavenoff and Bowen 1976; Kavenoff and Ryder 1976).

When imaged by electron microscopy, isolated chromosomes appeared as unbroken rosettes with a central core from which several tens of plectonemic loops radiate out (Fig. 1) (Delius and Worcel 1974; Kavenoff and Ryder 1976). This organization was sensitive to RNAse, suggesting a role for RNA in maintaining the integrity of the core (Kavenoff and Bowen 1976). Isolated chromosomes also showed a biphasic response to increased concentrations of ethidium bromide, indicating that DNA

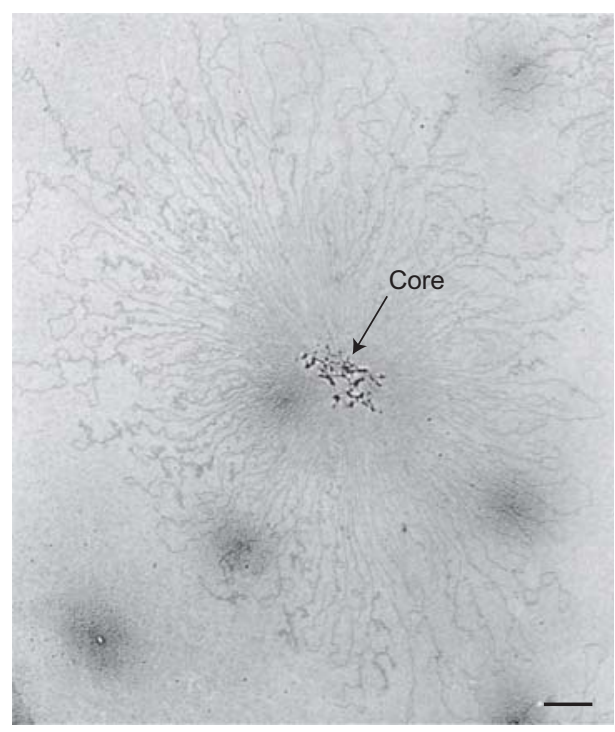

Figure 1. The "rosette" model of DNA organization. Electron micrograph of isolated membrane-free chromosomes from E. coli. The central core, from which several tens of loops radiate, is sensitive to RNAse. Single strand cuts to any one loop will only affect the supercoiling of that particular domain, leaving the rest of the chromosome unaffected. Bar $=1 \mu \mathrm{m}$. (reprinted from Kavenoff and Bowen 1976, with permission). 
supercoiling was maintained. Consistent with the electron microscopy studies, a few tens of DNAse catalyzed nicks are required to obtain a fully relaxed complex (Worcel and Burgi 1972).

The rosette model thus provided some of the first insights into the higher-order structure of the bacterial chromosome. The picture that emerged was one in which the chromosome consists of a central core held together by RNA-DNA interactions. Between 12-80 topologically independent loops_or "domains of supercoiling"-radiate out from this core (Fig. 1). Although all domains have the same amount of superhelicity, a single strand nick in one of the loops eliminates only the superhelicity in that particular domain, leaving the rest of the chromosome unaffected (Worcel and Burgi 1972). Importantly, the existence of domains of supercoiling has been confirmed by in vivo studies (Sinden and Pettijohn 1981; Scheirer and Higgins 2001; Postow et al. 2004). The presence of a stabilizing RNA “core," however, has been subject to certain skepticism because of the possibility of isolation-induced artifacts (Pettijohn 1982) and, to this day, the specific role of RNA in maintaining nucleoid structure is not understood.

Localization of DNA in Bacillus subtilis and Caulobacter: Specific Orientation

Because chromosomes isolated using the Stonington and Pettijohn method are separated from the rest of the cell, the rosette model does not make any predictions about the subcellular localization of any given DNA sequence. The first indication that the bacterial chromosome has a specific orientation within the cell came from genetic studies in Bacillus subtilis ( Wu and Errington 1994). Under starvation conditions, B. subtilis undergoes a sporulation program that divides the cell into a large mother cell compartment and a small forespore compartment (Barák and Wilkinson 2005). This asymmetric division traps $\sim 30 \%$ of the chromosome in the forespore, and segregation of the rest of the chromosome is driven by SpoIIIE (Burton et al. 2007; Ptacin et al. 2008; see also Dubnau 2010). In SpoIIIE mutant cells, DNA translocation failed to occur and $70 \%$ of the chromosome was left stranded in the mother cell. Wu and Errington (1994) discovered that the identity of the stranded DNA was reproducible from cell to cell, suggesting that the chromosome has a specific orientation with respect to the division septum, at least during sporulation.

A few years later, direct visualization of the position of chromosomal loci was achieved. Mohl and Gober (1997) showed that the Caulobacter ParB protein, which binds specifically to a site near the origin of replication (termed Cori in Caulobacter and ori $C$ in other bacteria), was localized consistently to the cell poles (Fig. 2A). Simultaneously, Webb and coworkers (Webb et al. 1997) adapted a method originally devised for visualizing DNA loci in eukaryotic cells (Robinett et al. 1996; Straight et al. 1996) to look at the position of oriC and the terminus of replication (ter) in B. subtilis. In this method, a large number $(\sim 250)$ of lacO sites, arranged in tandem, are inserted into the chromosome at a site of interest. Subsequent expression of a LacI-GFP fusion results in binding of LacI-GFP to the $\mathrm{lacO}$ arrays, and creates a localized fluorescent spot that can be visualized with a modern CCD camera. Using this method, Webb and coworkers confirmed the genetic prediction that the B. subtilis oriC localizes to the cell poles during sporulation. Furthermore, they showed that this localization pattern held true even in vegetatively growing cells, and that ter localized to the opposite pole in newborn cells (Fig. 2C,D) (Webb et al. 1997).

It is interesting to note that the total length of these lacO arrays is on the order of $10 \mathrm{~kb}$, which, if stretched out, would measure $\sim 3.4$ $\mu \mathrm{m}$; more than enough to span the length of the cell. Yet, in all cases examined, the arrays appeared as tight diffraction-limited foci. This observation is unlikely to be an artifact of the labeling procedure for two reasons: First, the version of LacI used in these experiments had a truncated carboxyl terminus that prevents dimers from associating with each other and making higher-order structures (Lau et al. 2003); and second, the same result was obtained in fixed cells with fluorescence in situ hybridization (FISH) probes of a similar length (Jensen 
E. Toro and L. Shapiro

A

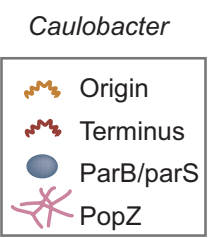

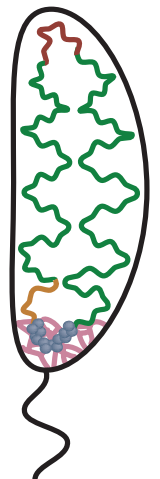

B
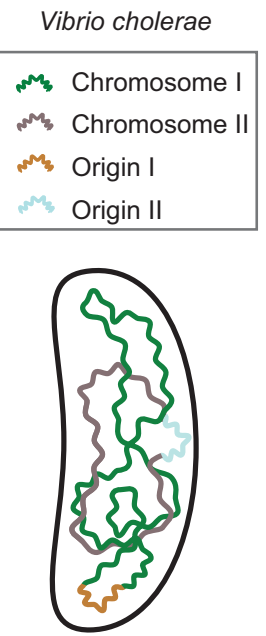

C
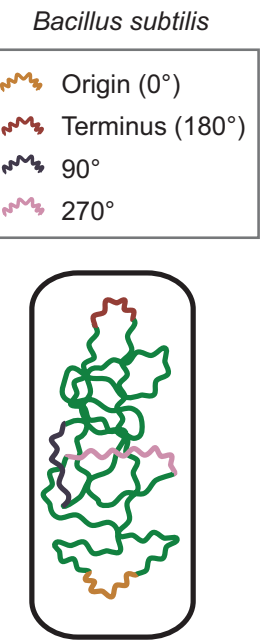

D

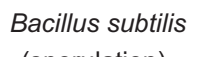
(sporulation)
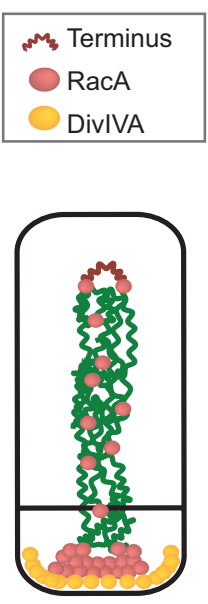

E Escherichia coli
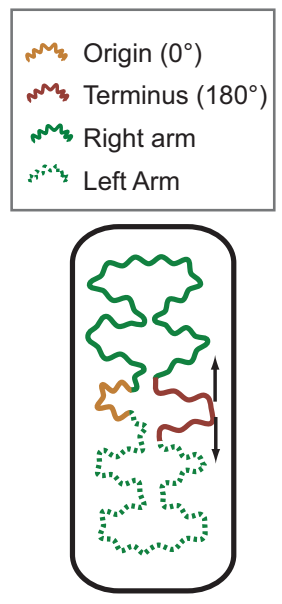

Figure 2. Chromosome organization in model bacteria. (A) The Caulobacter chromosome is linearly organized, and anchored to the flagellated pole via parS/ParB/PopZ. (B) In Vibrio cholerae, the origin region of the larger chromosome (chromosome I) is localized to the cell pole, whereas the origin of the smaller chromosome is localized to the cell center. The organization of the bulk of the chromosomes, as well as their separation or intermingling, are currently unknown. $(C)$ Four loci have been localized in vegetative cells of Bacillus subtilis, and their organization is reminiscent of the linear order seen in Caulobacter. Although the origin region is localized near to one pole, it appears not to be anchored to the cell membrane. $(D)$ Sporulating cells of B. subtilis, however, do anchor the origin region, through RacA/DivIVA, to the negatively curved membrane at the pole. RacA also binds all along the chromosome, compacting it into a long "axial filament" before sporulation. (E) The E. coli origin localizes to mid-cell, and the two replichores are separated into opposite cell halves. The terminus is broadly localized (arrows), and may be found on either side of the cell center.

and Shapiro 1999). Hence, it appears that in vivo DNA is highly and locally compacted.

The ability to synchronize Caulobacter cells played an important role in the next discovery, as it allowed investigators to easily follow the localization pattern of DNA through the cell cycle. Jensen and Shapiro (1999) used FISH to follow the positioning of Cori and ter in synchronized cells, and saw that Cori began the cell cycle at the old pole, whereas ter was localized to the new pole. After Cori duplicated, it quickly redistributed to a bipolar localization. Meanwhile, ter moved away from the pole and relocated to midcell. Near the end of the cell cycle, ter itself was duplicated, leaving a mirror image conformation of the chromosome (Jensen and Shapiro 1999).

Jensen and coworkers (2001) also looked at the localization pattern of members of the replication machinery. They found that the replisome formed near the old pole at the beginning of the cell cycle, close to Cori. As replication proceeded, the replisome migrated toward midcell, presumably being displaced from the pole by the accumulation of newly replicated DNA there.

Once it was established that both Cori and ter have rigorously defined cell-cycle-dependent localization, the question of how the rest of the chromosome is organized became more pressing (Breier and Cozzarelli 2004). Teleman and coworkers (Teleman et al. 1998) labeled four chromosomal positions $\left(359^{\circ}, 90^{\circ}, 181^{\circ}\right.$, and $270^{\circ}$ on the circular chromosome; oriC corresponds to $0^{\circ}$ ) in fixed $B$. subtilis cells, and concluded that loci at intermediate positions on the chromosome lie between oriC and ter 
High-order DNA Structure and Dynamics

inside the cell (Fig. 2C). A similar model was proposed for Caulobacter based on pulse labeling of the chromosome in synchronized cells. Early-replicated DNA was shown to localize near the cell poles, whereas late-replicated DNA localized closer to midcell, and intermediatereplicated DNA localized in between the two (Jensen et al. 2001).

These results suggested that in bacterial cells, the entire chromosome was organized, but definitive proof only came in 2004, when Viollier and coworkers (Viollier et al. 2004) developed computational methods to measure the position of fluorescent foci with subdiffraction precision and in a high-throughput manner. Using a transposon-based strategy, they created a set of 112 strains each carrying the lac $O$ arrays at a different position, and measured their location in $>500$ cells. They found a linear correspondence between the position of any given DNA locus on the chromosomal map and its position inside the cell. Thus, a locus that is $1 / 3$ of the distance between Cori and ter on the chromosome map will be found $1 / 3$ of the way between the old and new poles (Fig. 2A) (Viollier et al. 2004). It is important to remember that bacterial chromosomes are generally circular molecules, with the origin and terminus located at opposite ends of the circle. The two arms of the chromosome, or replichores, run parallel to each other from one cell pole to the other (Fig. 2A). Here, "linear organization" is used to refer to the linear relationship between a DNA locus's position in base pairs, and its subcellular location.

This striking organization raises the important question of how the chromosome is kept in place. Is there a site-or perhaps several sitesof attachment between the DNA and the cell envelope that ensures proper localization? Indeed, there are. During sporulation in B. subtilis, the RacA protein is required to bind the origin region of the chromosome to the cell pole (BenYehuda et al. 2003; Wu and Errington 2003). RacA binds preferentially to 25 sites in a large region around the origin of replication and interacts directly with DivIVA (Ben-Yehuda et al. 2005; Lenarcic et al. 2009). DivIVA, in turn, binds to negatively curved membranes, such as those that occur on the cytoplasmic side of cell poles (Lenarcic et al. 2009; Ramamurthi and Losick 2009). Hence, polar localization of the origin region of $B$. subtilis results from a pole-DivIVA-RacA-DNA (RacA binding sites) connection (Fig. 2D).

However, RacA is not expressed in vegetatively growing $B$. subtilis and the origin of replication does not appear to be anchored at the cell pole under these conditions (Fig. 2C). Ectopic expression of RacA during vegetative growth caused the chromosome to shift position so that it came in close contact with the pole (Ben-Yehuda et al. 2003). Therefore, the question of how the chromosome is kept oriented during vegetative growth in $B$. subtilis is still unsolved.

The case appears to be more straightforward in Caulobacter. Two groups recently showed that the Caulobacter chromosome is anchored at the cell pole by the PopZ protein (Bowman et al. 2008; Ebersbach et al. 2008). PopZ is a small, proline-rich protein that self-associates to form a network at the Caulobacter cell pole. It interacts directly with ParB, a sequence-specific DNA binding protein that binds to the parS sequence (about which, more later), which is only $8 \mathrm{~kb}$ away from Cori. Thus, in Caulobacter, the connection is: pole-PopZ-ParB-DNA ( parS) (Fig. $2 \mathrm{~A}$ ). Importantly, it was later shown that the polar localization of the origin of replication is not mediated by anchoring of Cori itself to the pole. When Cori was moved 100kb away from parS, its position in the cell shifted away from the pole (Toro et al. 2008). The polar position of parS, however, remained unchanged. Therefore, in contrast to previous belief, the determinants of chromosome orientation are not contained within the origin of replication.

Localization of DNA in E. coli: Replichore Separation and Nonrandom Segregation

Chromosome organization in E. coli appeared, at first, to be similar to that of B. subtilis and Caulobacter, with oriC at one pole and ter at the other (Gordon et al. 1997; Niki and Hiraga 1998; Bates and Kleckner 2005). Later work, however, showed a different, more complex 
E. Toro and L. Shapiro

picture. At the beginning of the cell cycle, slowly growing E. coli cells place oriC at midcell (Fig. 2E) (Nielsen et al. 2006b; Wang et al. 2006). FISH analysis suggested that the chromosome is linearly ordered in the cell, as in Caulobacter, but not along the ori-ter axis (Niki et al. 2000). Double-labeling experiments showed that each chromosomal arm, or replichore, localizes to a separate cell half (Nielsen et al. 2006b; Wang et al. 2006). The terminus region is broadly distributed, colocalizing with the left and right replichores in equal proportion (Fig. 2E, arrows) (Wang et al. 2006).

After duplication, the two E. coli oriC move to quarter cell positions and the bulk of the chromosome assumes a $<\mathrm{L}-\mathrm{R}-\mathrm{L}-\mathrm{R}>$ configuration (L and $\mathrm{R}$ refer to the Left and Right replichores, respectively) (Fig. 3) (Nielsen et al. 2006b; Wang et al. 2006). Counter-intuitively, this translationally symmetric (as opposed to mirror-symmetric) organization of the replichores predicts mirror symmetry with regards to segregation of the leading versus lagging strands of replication (Wang et al. 2006). To achieve the <L-R-L-R $>$ configuration observed, both leading strands have to be segregated to the distal edges of the cell while the lagging strands stay proximal, or vice-versa (White et al. 2008). Otherwise, the chromosome would toggle between configurations (see Fig. 4 for why this is so). Indeed, White and coworkers showed that leading strands are segregated to the edges of the cell. Using an ingenious method, they induced the specific degradation, in vivo, of the lagging-strandreplicated copy of one locus in the E. coli chromosome. By examining the localization of the remaining, leading-strand-replicated copy, they showed that in $\sim 90 \%$ of cells, the leading strand is segregated to the outside edges of the cell (Fig. 4B, right) (White et al. 2008).

It should be noted that this leading strand preference for the outer edges of the cell does not necessarily lead to "immortal strand" segregation, which postulates nonrandom segregation of "old" and "new" DNA strands (Lansdorp 2007; Lew et al. 2008). Because of the semiconservative nature of DNA replication, every round of synthesis produces two chromosomes composed each

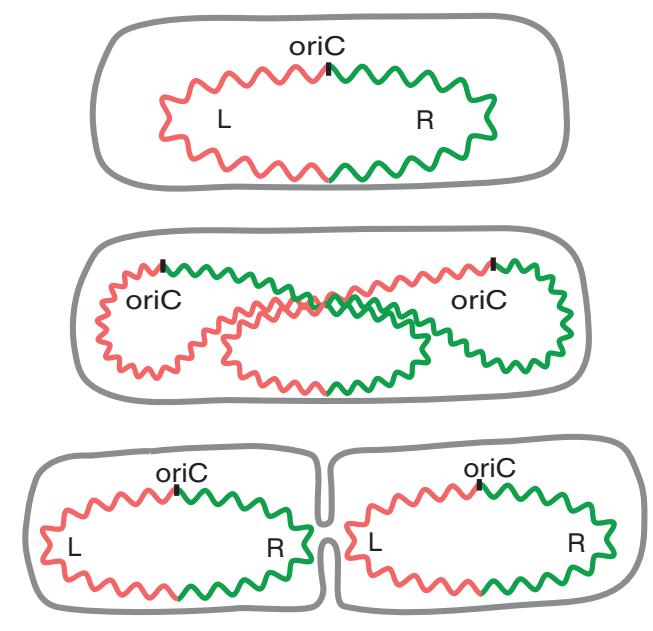

Figure 3. Chromosome organization in E. coli. The origin of replication of the E. coli chromosome (oriC) is located at midcell, and each arm is kept in a separate cell half (top). The terminus region is broadly distributed along the long axis of the cell (not shown). As replication proceeds (middle), each daughter oriC is segregated to the cell quarters and, when replication is complete, the daughter chromosomes adopt a translationally symmetric <L-R-L-R $>$ configuration (bottom).

of a newly synthesized strand annealed to an old strand. Similarly, every round of cell division produces two cells each with a newly synthesized cell pole as well as an old pole. The immortal strand hypothesis postulates that old DNA will be reliably partitioned to the old pole, thus generating a stable and potentially infinite association of one particular pole with one particular strand of DNA. Thus, the origin of the phrase-immortal strand segregation.

The leading versus lagging strand segregation discovered by White and coworkers, then, is slightly different from immortal strand segregation (see Fig. 5 for a visual explanation of this complicated point). Under leading strand segregation, it is possible for a given "old" pole to receive either daughter chromosome. As long as the leading strand of that chromosome is positioned closer to the old pole, White's law is not broken, even though the immortal strand hypothesis may not be kept. This situation, however, will change the chromosomal configuration in successive generations from 
A

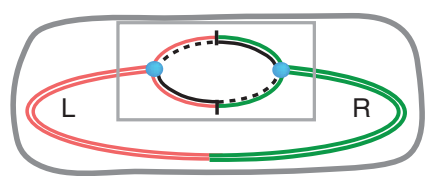

B

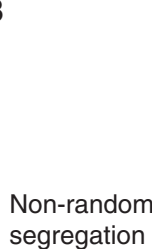
segregation

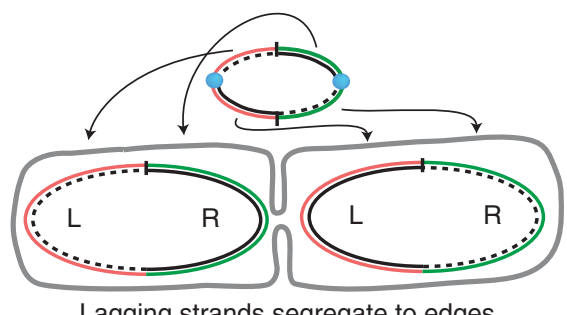

C

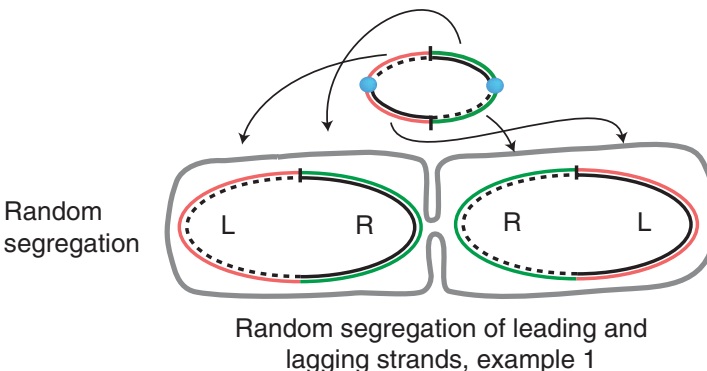

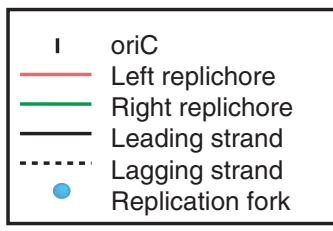

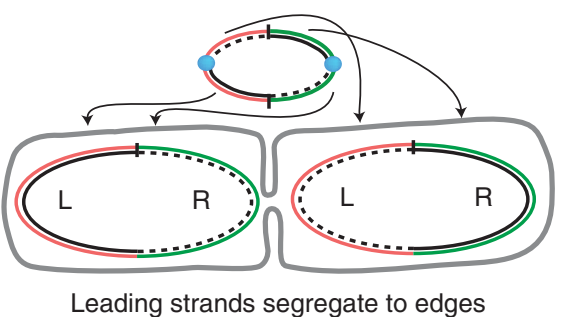

Leading strands segregate to edges

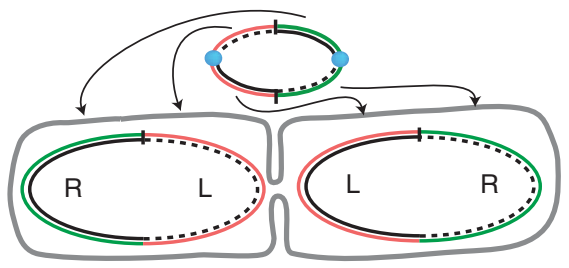

Random segregation of leading and lagging strands, example 2

Figure 4. Nonrandom segregation in E. coli. (A) A replicating mother cell is shown, highlighting the Left and Right replichores as well as the difference between leading-strand-replicated (solid black lines) and lagging-strand-replicated DNA (dashed black lines). The replication bubble (gray box) is also shown, and repeated above each example in $B$ and $C$ to illustrate the origin of each configuration. $(B)$ To achieve the $<$ L-R-L-R > configuration seen, it is necessary for both lagging strands or both leading strands to be segregated to the distal edges of the cell. Note that in $\sim 90 \%$ of cases, leading strand segregation to the distal edges (right) is observed. $(C)$ If random segregation of leading and lagging strands is imposed, the $<$ L-R-L-R $>$ configuration cannot be achieved, and mirror symmetry appears (e.g., $<$ L-R-R-L $>$ ).

$<$ L-R-L-R $>$ to $<$ R-L-R-L $>$ (Fig. 5 , bottom). Thus, by following two markers in successive generations, it is possible to measure the degree to which E. coli undergoes immortal strand segregation, something that Wang and coworkers (Wang et al. 2006) measured: Of 17 divisions observed, 12 kept the $<\mathrm{L}-\mathrm{R}-\mathrm{L}-\mathrm{R}>$ configuration, four changed to mirror symmetry ( $<\mathrm{L}-\mathrm{R}-\mathrm{R}-\mathrm{L}>$ or $<\mathrm{R}-\mathrm{L}-\mathrm{L}-\mathrm{R}>$ ), and one reversed to $<\mathrm{R}-\mathrm{L}-$ R-L $>$. Hence, although $\sim 90 \%$ of cells showed nonrandom leading-strand segregation, immortal strand segregation occurred in only $\sim 70 \%$ $(12 / 17)$ of cell divisions.

The immortal strand hypothesis has also been tested in Caulobacter (Osley and Newton 1974; Marczynski et al. 1990) and B. subtilis
(Errington and Wake 1991), and in both cases it was found that chromosomes segregate randomly to daughter cells. Because neither of these species distinguishes between the Left and Right replichores, nonrandom segregation may be related to the orientation of the chromosome within the cell.

\section{DNA SEGREGATION}

The Replicon Model: Cell Growth as the Driver of Segregation

By far, the most influential hypothesis about bacterial segregation was the replicon model proposed by François Jacob, Sydney Brenner, 
A

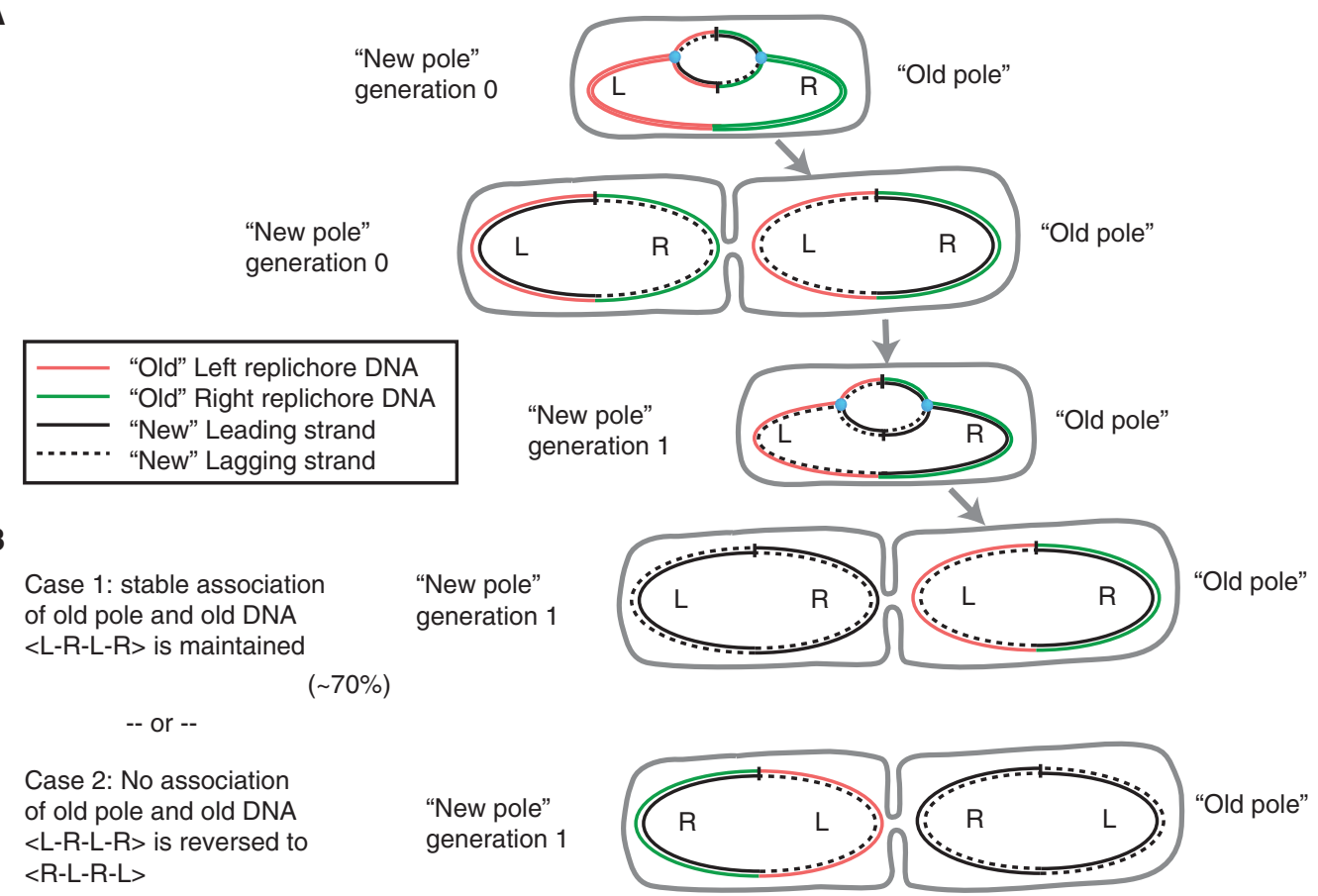

Figure 5. "Immortal strand" inheritance versus Leading strand segregation. Two generations of DNA replication and segregation are shown, to illustrate the association of an old DNA strand (colored) with the old cell pole. Note that in all cases, leading strand segregation to the distal cell edges is maintained. $(A)$ After the first generation, both daughter cells carry one "new" and one "old" strand of DNA (black and colored, respectively). (B) During the second round of segregation, two scenarios are possible: (1) immortal strand segregation is kept, and the "old" pole stays associated with the "old" (colored) strand of DNA (top). Note that this is the case observed for E. coli cells in $\sim 70 \%$ of cases; (2) Immortal strand segregation is not kept, and the "old" pole received two "new" strands of DNA. In this case, the configuration of the chromosome changes from $<\mathrm{L}-\mathrm{R}-\mathrm{L}-\mathrm{R}>$ to $<\mathrm{R}-\mathrm{L}-\mathrm{R}-\mathrm{L}>$.

and François Cuzin in 1963 (Jacob et al. 1963). In a small section at the end of a paper dealing mostly with replication control, Jacob and coworkers noted that puzzling observations about the efficiency of conjugation as well as thin section electron micrographs were consistent with the anchoring of specific sections of DNA to the cell envelope. Hence, if sister chromosomes are attached to the cell membrane and growth takes place in between the two attachment sites, DNA segregation could be achieved passively as a byproduct of cell elongation.

In order for the Jacob model to be possible, two things must be true: First, the chromosome must be physically attached to the cell wall at a specific site; and second, the cell wall must grow in a nonuniform manner. These predictions led investigators to look for a specific association of the origin of replication with the membrane, which was found to be present in several species (Sueoka and Quinn 1968; Fielding and Fox 1970; Bowman et al. 2008; Ebersbach et al. 2008), as well as zonal cell wall growth, which was found to be present or absent, depending on the organism (Cole and Hahn 1962; Mobley et al. 1984; Aaron et al. 2007).

Many of the observed associations between DNA and membrane were sensitive to rifampin, a transcription inhibitor (Dworsky and Schaechter 1973), suggesting that they were mediated by transertion (i.e., coupled transcription, translation, and insertion of the nascent polypeptide into the membrane). However, some of the 
High-order DNA Structure and Dynamics

DNA-membrane interactions were impervious to rifampin, implying that at least some sites on the chromosome, including oriC, were specifically anchored to the cell envelope by DNA binding proteins (Jacq and Kohiyama 1980). As mentioned previously, the chromosomeanchoring proteins for Caulobacter (ParBPopZ) and B. subtilis (RacA-DivIVA) are now known (Fig. 2).

Two other observations seemed to support the replicon model: First, bacterial nucleoids stained with nonspecific DNA binding dyes appeared to separate gradually, in contrast to what happens in eukaryotes (Van Helvoort and Woldringh 1994); and second, early genetic screens for partitioning mutants in E. coli yielded hits involved in resolving topological problems associated with segregation (Hiraga et al. 1989; Adams et al. 1992; Drlica 1992), but no proteins that could provide the force to drive movement (Wheeler and Shapiro 1997). In the absence of force-generating proteins, passive segregation seemed the logical alternative.

It should be noted that the E. coli MukB protein, identified in a genetic screen for DNA partitioning mutants, was briefly hailed as the missing molecular motor based on the fact that it existed as a DNA-binding homodimer that could bind ATP/GTP and had a coiled-coil domain, a characteristic of motors like myosin and kinesin (Niki et al. 1992; Wake and Errington 1995). MukB turned out not to be a motor, however. The characterization of the $B$. subtilis SMC condensation complex (Britton et al. 1998; Moriya et al. 1998) later led to the realization that MukB is in fact part of the E. coli analogue of SMC (Bartosik and Jagura-Burdzy 2005).

Nondedicated Models of Segregation: Fast, Progressive Segregation in the Absence of a Mitotic Apparatus

Despite the popularity of the replicon model, evidence against it began mounting. Not only did zonal growth appear to be limited to a subset of species, as soon as direct labeling of specific DNA loci in living cells was achieved, it became clear that their speed of movement was too fast to be accounted for by cell growth (Gordon et al. 1997; Mohl and Gober 1997; Webb et al. 1997; Teleman et al. 1998; Jensen and Shapiro 1999; Viollier et al. 2004). Live tracking experiments also showed that chromosome segregation is progressive; that is, DNA loci were separated while replication was still ongoing (Viollier et al. 2004; Nielsen et al. 2006a). Interestingly, this is not an absolute rule. In $E$. coli, there is evidence that the origin region undergoes a short period of "sister chromatid cohesion," after which the entire region is segregated as a single unit (Bates and Kleckner 2005; Espeli et al. 2008). Other regions of the E. coli chromosome, however, segregate progressively (Nielsen et al. 2006a).

Abrupt DNA separation, coupled to the fact that no force-generating segregation proteins had been found, paved the way for a new wave of "nondedicated" models whose aim was to explain fast segregation in the absence of a mitotic apparatus. Several interesting proposals were put forth. It was hypothesized that the force produced by DNA polymerase (Lemon and Grossman 2001) or RNA polymerase (Dworkin and Losick 2002) could help separate daughter chromosomes. Intriguingly, it was also suggested that DNA segregation may be a selforganizing process, driven by separation of transertion domains (Woldringh 2002), or by entropic exclusion of sister chromosomes (Jun and Mulder 2006). Each of these models is supported by a subset of observations, and it is possible that these mechanisms contribute to bulk DNA segregation (Toro et al. 2008). However, none can fully explain the diverse behaviors observed in vivo.

\section{Dedicated Models of Segregation: A Mitotic-like Apparatus}

Around the same time that nondedicated models were being proposed, new observations began to suggest that perhaps a mitotic-like apparatus did exist in bacteria. We have already mentioned the transient suggestion that MukB could be a molecular motor in charge of driving chromosome segregation. A second, more 
promising candidate for force generation is the ParABS system.

Low copy number plasmids like the E. coli P1 prophage are inherited with high efficiency despite the fact that as few as two copies of the plasmid may be present before division (Prentki et al. 1977). These observations suggested that such plasmids contained a partitioning system, and deletion of $\mathrm{P} 1$ fragments showed that the ParABS locus was necessary and sufficient to confer stability to low copy number replicons (Abeles et al. 1985). This locus contains three components: ParB, a sequence-specific DNA binding protein that binds to the parS sequence; and ParA, a Walker type ATPase that has been shown to polymerize and/or oscillate over the nucleoid in several partition systems (Surtees and Funnell 2003; also see Mullins 2010).

Hence, by the early 2000s, it was clear that plasmid partitioning was actively mediated by the ParABS system, and also that the chromosomes of most bacteria (but not E. coli) contained homologs of the par locus. Based on sequence comparisons of their constituent ParA ATPases, chromosomal ParABS systems are distinct from plasmid ones (Gerdes et al. 2000). Nevertheless, the hypothesis that ParABS systems could indeed drive the segregation of bacterial chromosomes was supported by experiments showing that: (1) deletion/depletion of ParABS components resulted in higher proportions of anucleate cells (Ireton et al. 1994; Mohl and Gober 1997); and (2) addition of various chromosomal ParABS systems to an unstable plasmid increased its efficiency of transmission (Godfrin-Estevenon et al. 2002; Dubarry et al. 2006).

Work in Vibrio cholerae has been instrumental in demonstrating the importance of the ParABS system for segregation. $V$. cholerae carries two chromosomes (Fig. 2B), each with their own distinct segregation dynamics and ParABS system, and the larger of which (chromosome I) shows a segregation pattern reminiscent of that observed in Caulobacter (Fogel and Waldor 2005). Work by Fogel and Waldor (2006) showed that $\operatorname{par}_{I}$ segregates ahead of ori $C_{I}$, suggesting that it may act as the chromosomal centromere (i.e., the site of force exertion during segregation). Toro and coworkers (2008) expanded this observation in Caulobacter and found that parS invariably segregated ahead of all other loci, regardless of the order of replication. Furthermore, segregation was delayed when parS was moved to a site farther away from the origin of replication, indicating that segregation cannot begin before parS is duplicated. This showed that, at least in Caulobacter, nondedicated models of segregation are unable to initiate segregation.

How might the ParABS system perform its segregation function? Based on time-lapse observations of $\operatorname{ParA}_{\mathrm{I}}$ and $\mathrm{ParB}_{\mathrm{I}}$ dynamics, Fogel and Waldor proposed a pulling mechanism. In V. cholerae, ParA $_{\mathrm{I}}$ forms a fluorescence "cloud" that grows from the pole opposite to $\operatorname{parS}_{I}$. When it reaches parS , the cloud switches from growth to contraction, and one of the newly duplicated copies of $\operatorname{ParB}_{\mathrm{I}}$ follows the receding edge of the cloud until it reaches the opposite pole (Fogel and Waldor 2006). This mechanism is by no means proven, but it is certainly compelling. Work is currently under way to try to characterize the biochemical and structural characteristics of this system (Hester and Lutkenhaus 2007; Castaing et al. 2008).

Despite the promising results outlined above, some important aspects of the ParABS system remain to be explored. New work in B. subtilis has shown a link between ParA (Soj) and chromosome replication (Murray and Errington 2008), as well as a direct interaction between ParB (Spo0J) and the SMC complex (Gruber and Errington 2009; Sullivan et al. 2009). Thus, the perverse and often baffling results of soj and spo0J deletion in B. subtilis may be explained by a shift in function.

Compounding the issue, several species (with the exception of Caulobacter and $V$. cholerae chromosome II) still segregate their chromosome normally in most cells even when ParABS is inactivated (Ireton et al. 1994; Lewis et al. 2002; Fogel and Waldor 2006; Jakimowicz et al. 2007; Yamaichi et al. 2007). This suggests that there are redundant mechanisms that ensure chromosome segregation in the absence of ParABS. It has been proposed that the actin-like MreB protein contributes 
to DNA segregation (Gitai et al. 2005; Kruse et al. 2006; Hu et al. 2007; Karczmarek et al. 2007; Shebelut et al. 2009; see also Gitai 2010). Another candidate is the migs sequence found in E. coli (recall that E. coli does not contain a ParABS system on its chromosome).

migS was found by Yamaichi and Niki by cleverly forcing the cells to break off pieces of the chromosome and using them to create mini-chromosomes (Yamaichi and Niki 2004). Thus, the genome within the cell remains unchanged except for the fact that now a small piece of the chromosome is on a separate molecule. Using this strategy, Yamaichi and Niki found that the presence, in cis, of a $25 \mathrm{bp}$ sequence ( $m i g S$ ) was required for proper separation of oriC-proximal DNA, as measured by FISH. migS did not stabilize plasmids nor cause them to localize to a particular subcellular location (Yamaichi and Niki 2004). Despite this, there is good evidence that migS plays an important role in the segregation of the E. coli chromosome (Fekete and Chattoraj 2005).

\section{CONCLUDING REMARKS}

\section{What We Know Thus Far}

Taking into account all of the above, we can make the following generalizations about chromosome organization and segregation in bacteria: The circular chromosome exists within the cell as a compact structure that is organized into separate superhelical domains. At least one locus, and perhaps several, are specifically positioned within the cell, and the rest of the chromosome is kept linearly organized with respect to those landmarks. DNA is kept highly compacted at the local level by a balance of forces, including supercoiling, compaction by proteins, transcription, transertion, and perhaps even RNA-DNA interactions.

Segregation is mediated by an active and dedicated mechanism of which we know very little. In the case of bacteria like E. coli, which maintain the origin region at midcell and left and right replichores in separate cell halves, segregation is nonrandom and the leading strandreplicated arms are shuttled to the outer edges of the cell. Such distinction is not made in Caulobacter or B. subtilis, which keep the origin and terminus regions at opposite poles and do not appear to differentiate between the left and right replichores. Progressive segregation, coupled to fast and directed movement of the origin region at the beginning of replication, collaborate to duplicate the organization of the mother chromosome in each daughter cell.

\section{Pressing Matters for the Future}

Several critical questions remain to be explored with regards to chromosomal organization in all bacteria. We lack a mechanistic understanding of the requirements for maintaining chromosome orientation inside cells. Is one anchoring point enough to orient the entire chromosome, or do other sites need to be specifically positioned as well? In species like E. coli and B. subtilis, which apparently do not anchor the origin region to the pole during vegetative growth, are there compensating anchoring sites elsewhere? Indeed, does proper chromosome orientation always require an anchoring point to the cell envelope? It is known, for instance, that plasmids are positioned to specific subcellular locations in a self-organizing manner that does not seem to make use of membrane anchors (Ho et al. 2002; Garner et al. 2007). Hence, membrane anchors may be optional. On the other hand, early biochemical experiments in several bacteria-including E. colishowed that multiple chromosomal sites, including not only the region around oriC but also the terminus and the site of ongoing replication, are found to associate with the membrane (Ryter 1968; Leibowitz and Schaechter 1975; Hendrickson et al. 1982). Perhaps, then, nonpolar anchoring sites exist in these organisms.

It is also still unclear why the chromosome is kept in a linear order within the cell, and not in the "bowl of spaghetti" configuration assumed in the past. This is a place in which physical modeling of polymers in confined spaces (e.g., Jun and Mulder 2006) may help guide our intuition. For example, linearity may be a simple consequence of progressive segregation 
and DNA compaction, i.e., as the DNA is segregated, it takes up space near the pole, forcing subsequent segments of the chromosome to reside farther away, with a simple linear dependence.

As for segregation, two avenues of investigation are likely to yield exciting results. On the one hand, understanding the mechanism of action of the ParABS and migS systems is of obvious importance. On the other hand, the fact that most bacteria seem to live surprisingly happy lives in the absence of ParABS or migS implies that there are other mechanisms at work. It is still unclear whether these are dedicated fail-safes, serendipitous consequences of other molecular machines (e.g., polymerases), or self-organizing processes.

Answering all of these questions will require new technologies and ingenious experiments, as well as an understanding of the similarities and differences between model systems. We expect the field of chromosome organization and segregation to be active and exciting in the coming years.

\section{ACKNOWLEDGMENTS}

The authors wish to thank A. Raphael and S. Goodwin for critical reading of the manuscript. Work in the Shapiro laboratory is supported by National Institutes of Health grants R01 GM5 1426 R24 and GM073011-04.

\section{REFERENCES}

Aaron M, Charbon G, Lam H, Schwarz H, Vollmer W, Jacobs-Wagner C. 2007. The tubulin homologue FtsZ contributes to cell elongation by guiding cell wall precursor synthesis in Caulobacter crescentus. Mol Microbiol 64: 938-952.

Abeles AL, Friedman SA, Austin SJ. 1985. Partition of unitcopy miniplasmids to daughter cells. III. The DNA sequence and functional organization of the $\mathrm{P} 1$ partition region. J Mol Biol 185: 261-272.

Adams DE, Shekhtman EM, Zechiedrich EL, Schmid MB, Cozzarelli NR. 1992. The role of topoisomerase IV in partitioning bacterial replicons and the structure of catenated intermediates in DNA replication. Cell 71:277-288.

Barák I, Wilkinson AJ. 2005. Where asymmetry in gene expression originates. Mol Microbiol 57: 611-620.

Bartosik AA, Jagura-Burdzy G. 2005. Bacterial chromosome segregation. Acta Biochim Pol 52: 1-34.
Bates D, Kleckner N. 2005. Chromosome and replisome dynamics in E. coli: Loss of sister cohesion triggers global chromosome movement and mediates chromosome segregation. Cell 121: 899-911.

Ben-Yehuda S, Rudner DZ, Losick R. 2003. RacA, a bacterial protein that anchors chromosomes to the cell poles. Science 299: 532-536.

Ben-Yehuda S, Fujita M, Liu XS, Gorbatyuk B, Skoko D, Yan J, Marko JF, Liu JS, Eichenberger P, Rudner DZ, et al. 2005. Defining a centromere-like element in Bacillus subtilis by identifying the binding sites for the chromosome-anchoring protein RacA. Mol Cell 17: $773-782$.

Bowman GR, Comolli LR, Zhu J, Eckart M, Koenig M, Downing KH, Moerner WE, Earnest T, Shapiro L. 2008. A polymeric protein anchors the chromosomal origin/ ParB complex at a bacterial cell pole. Cell 134: 945-955.

Breier AM, Cozzarelli NR. 2004. Linear ordering and dynamic segregation of the bacterial chromosome. Proc Natl Acad Sci 101: 9175-9176.

Britton RA, Lin DC, Grossman AD. 1998. Characterization of a prokaryotic SMC protein involved in chromosome partitioning. Genes Dev 12: 1254-1259.

Burton BM, Marquis KA, Sullivan NL, Rapoport TA, Rudner DZ. 2007. The ATPase SpoIIIE transports DNA across fused septal membranes during sporulation in Bacillus subtilis. Cell 131: 1301-1312.

Castaing JP, Bouet JY, Lane D. 2008. F plasmid partition depends on interaction of SopA with non-specific DNA. Mol Microbiol 70: 1000-1011.

Cole RM, Hahn JJ. 1962. Cell wall replication in Streptococcus pyogenes. Science 135: 722-724.

Delius H, Worcel A. 1974. Electron microscopic studies on the folded chromosome of Escherichia coli. Cold Spring Harb Symp Quant Biol 38: 53-58.

Drlica K. 1992. Control of bacterial DNA supercoiling. Mol Microbiol 6: 425-433.

Dubarry N, Pasta F, Lane D. 2006. ParABS systems of the four replicons of Burkholderia cenocepacia: New chromosome centromeres confer partition specificity. J Bacteriol 188: 1489-1496.

Dubnau D. 2010. DNA pumps. Cold Spring Harb Perspect Biol 2: a000406.

Dworkin J, Losick R. 2002. Does RNA polymerase help drive chromosome segregation in bacteria? Proc Natl Acad Sci 99: 14089-14094.

Dworsky P, Schaechter M. 1973. Effect of rifampin on the structure and membrane attachment of the nucleoid of Escherichia coli. J Bacteriol 116: 1364-1374.

Ebersbach G, Briegel A, Jensen GJ, Jacobs-Wagner C. 2008. A self-associating protein critical for chromosome attachment, division, and polar organization in caulobacter. Cell 134: 956-968.

Errington J, Wake RG. 1991. Chromosome strand segregation during sporulation in Bacillus subtilis. Mol Microbiol 5: 1145-1149.

Espeli O, Mercier R, Boccard F. 2008. DNA dynamics vary according to macrodomain topography in the E. coli chromosome. Mol Microbiol 68: 1418-1427. 
Fekete RA, Chattoraj DK. 2005. A cis-acting sequence involved in chromosome segregation in Escherichia coli. Mol Microbiol 55: 175-183.

Fielding P, Fox CF. 1970. Evidence for stable attachment of DNA to membrane at the replication origin of Escherichia coli. Biochem Biophys Res Commun 41: 157-162.

Fogel MA, Waldor MK. 2005. Distinct segregation dynamics of the two Vibrio cholerae chromosomes. Mol Microbiol 55: 125-136.

Fogel MA, Waldor MK. 2006. A dynamic, mitotic-like mechanism for bacterial chromosome segregation. Genes Dev 20: 3269-3282.

Garner EC, Campbell CS, Weibel DB, Mullins RD. 2007. Reconstitution of DNA segregation driven by assembly of a prokaryotic actin homolog. Science 315: 1270-1274.

Gerdes K, Møller-Jensen J, Bugge Jensen R. 2000. Plasmid and chromosome partitioning: Surprises from phylogeny. Mol Microbiol 37: 455-466.

Gitai Z. 2010. The structure and function of bacterial actin and microfilaments. Cold Spring Harb Perspect Biol 2: a000364.

Gitai Z, Dye NA, Reisenauer A, Wachi M, Shapiro L. 2005. MreB actin-mediated segregation of a specific region of a bacterial chromosome. Cell 120: 329-341.

Godfrin-Estevenon AM, Pasta F, Lane D. 2002. The parAB gene products of Pseudomonas putida exhibit partition activity in both P. putida and Escherichia coli. Mol Microbiol 43: 39-49.

Gordon GS, Sitnikov D, Webb CD, Teleman A, Straight A, Losick R, Murray AW, Wright A. 1997. Chromosome and low copy plasmid segregation in E. coli: Visual evidence for distinct mechanisms. Cell 90: 1113-1121.

Gruber S, Errington J. 2009. Recruitment of condensin to replication origin regions by $\mathrm{ParB} / \mathrm{SpoOJ}$ promotes chromosome segregation in B. subtilis. Cell 137: 685-696.

Hendrickson WG, Kusano T, Yamaki H, Balakrishnan R, King M, Murchie J, Schaechter M. 1982. Binding of the origin of replication of Escherichia coli to the outer membrane. Cell 30: 915-923.

Hester CM, Lutkenhaus J. 2007. Soj (ParA) DNA binding is mediated by conserved arginines and is essential for plasmid segregation. Proc Natl Acad Sci 104: 20326-20331.

Hiraga S, Niki H, Ogura T, Ichinose C, Mori H, Ezaki B, Jaffé A. 1989. Chromosome partitioning in Escherichia coli: Novel mutants producing anucleate cells. J Bacteriol 171: $1496-1505$.

Ho TQ, Zhong Z, Aung S, Pogliano J. 2002. Compatible bacterial plasmids are targeted to independent cellular locations in Escherichia coli. EMBO J 21: 1864-1872.

Hu B, Yang G, Zhao W, Zhang Y, Zhao J. 2007. MreB is important for cell shape but not for chromosome segregation of the filamentous cyanobacterium Anabaena sp. PCC 7120. Mol Microbiol 63: 1640-1652.

Ireton K, Gunther NW, Grossman AD. 1994. spo0J is required for normal chromosome segregation as well as the initiation of sporulation in Bacillus subtilis. J Bacteriol 176: $5320-5329$.

Jacob F, brenner S, Cuzin F. 1963. On the regulation of DNA replication in bacteria. Cold Spring Harbor Symp Quant Biol 28: 329-348.
Jacq A, Kohiyama M. 1980. A DNA-binding protein specific for the early replicated region of the chromosome obtained from Escherichia coli membrane fractions. Eur J Biochem 105: 25-31.

Jakimowicz D, Brzostek A, Rumijowska-Galewicz A, Zydek P, Dołzbłasz A, Smulczyk-Krawczyszyn A, Zimniak T, Wojtasz L, Zawilak-Pawlik A, et al. 2007. Characterization of the mycobacterial chromosome segregation protein ParB and identification of its target in Mycobacterium smegmatis. Microbiology 153: 4050-4060.

Jensen RB, Shapiro L. 1999. The Caulobacter crescentus smc gene is required for cell cycle progression and chromosome segregation. Proc Natl Acad Sci 96: 10661-10666.

Jensen RB, Wang SC, Shapiro L. 2001. A moving DNA replication factory in Caulobacter crescentus. EMBO J 20: $4952-4963$.

Jun S, Mulder B. 2006. Entropy-driven spatial organization of highly confined polymers: Lessons for the bacterial chromosome. Proc Natl Acad Sci 103: 12388-12393.

Karczmarek A, Martínez-Arteaga R, Baselga RM, Alexeeva S, Hansen FG, Vicente M, Nanninga N, den Blaauwen T. 2007. DNA and origin region segregation are not affected by the transition from rod to sphere after inhibition of Escherichia coli MreB by A22. Mol Microbiol 65: $51-63$.

Kavenoff R, Bowen BC. 1976. Electron microscopy of membrane-free folded chromosomes from Escherichia coli. Chromosoma 59: 89-101.

Kavenoff R, Ryder OA. 1976. Electron microscopy of membrane-associated folded chromosomes of Escherichia coli. Chromosoma 55: 13-25.

Kellenberger E. 1991. Functional consequences of improved structural information on bacterial nucleoids. Res Microbiol 142: 229-238.

Kruse T, Blagoev B, Løbner-Olesen A, Wachi M, Sasaki K, Iwai N, Mann M, Gerdes K. 2006. Actin homolog MreB and RNA polymerase interact and are both required for chromosome segregation in Escherichia coli. Genes Dev 20: $113-124$.

Lansdorp PM. 2007. Immortal strands? Give me a break. Cell 129: 1244-1247.

Lau IF, Filipe SR, Søballe B, Økstad OA, Barre FX, Sherratt DJ. 2003. Spatial and temporal organization of replicating Escherichia coli chromosomes. Mol Microbiol 49: 731-743.

Leibowitz PJ, Schaechter M. 1975. The attachment of the bacterial chromosome to the cell membrane. Int Rev Cytol 41: 1-28.

Lemon KP, Grossman AD. 2001. The extrusion-capture model for chromosome partitioning in bacteria. Genes Dev 15: 2031-2041.

Lenarcic R, Halbedel S, Visser L, Shaw M, Wu LJ, Errington J, Marenduzzo D, Hamoen LW. 2009. Localisation of DivIVA by targeting to negatively curved membranes. EMBO J 28: 2272-2282.

Lew DJ, Burke DJ, Dutta A. 2008. The immortal strand hypothesis: How could it work? Cell 133: 21-23.

Lewis RA, Bignell CR, Zeng W, Jones AC, Thomas CM. 2002. Chromosome loss from par mutants of Pseudomonas putida depends on growth medium and phase of growth. Microbiology 148: 537-548. 
Marczynski GT, Dingwall A, Shapiro L. 1990. Plasmid and chromosomal DNA replication and partitioning during the Caulobacter crescentus cell cycle. J Mol Biol 212: 709-722.

Mobley HL, Koch AL, Doyle RJ, Streips UN. 1984. Insertion and fate of the cell wall in Bacillus subtilis. J Bacteriol 158: $169-179$.

Mohl DA, Gober JW. 1997. Cell cycle-dependent polar localization of chromosome partitioning proteins in Caulobacter crescentus. Cell 88: 675-684.

Moriya S, Tsujikawa E, Hassan AK, Asai K, Kodama T, Ogasawara N. 1998. A Bacillus subtilis gene-encoding protein homologous to eukaryotic SMC motor protein is necessary for chromosome partition. Mol Microbiol 29: $179-187$.

Mullins D. 2010. Bacterial cytoskeleton: The function of FtsZ and ParA polymers. Cold Spring Harb Perspect Biol 2: a002550.

Murray H, Errington J. 2008. Dynamic control of the DNA replication initiation protein DnaA by Soj/ParA. Cell 135: 74-84.

Nielsen HJ, Li Y, Youngren B, Hansen FG, Austin S. 2006a. Progressive segregation of the Escherichia coli chromosome. Mol Microbiol 61: 383-393.

Nielsen HJ, Ottesen JR, Youngren B, Austin SJ, Hansen FG. 2006b. The Escherichia coli chromosome is organized with the left and right chromosome arms in separate cell halves. Mol Microbiol 62: 331-338.

Niki H, Hiraga S. 1998. Polar localization of the replication origin and terminus in Escherichia coli nucleoids during chromosome partitioning. Genes Dev 12: 1036-1045.

Niki H, Imamura R, Kitaoka M, Yamanaka K, Ogura T, Hiraga S. 1992. E.coli MukB protein involved in chromosome partition forms a homodimer with a rod-andhinge structure having DNA binding and ATP/GTP binding activities. EMBO J 11: 5101-5109.

Niki H, Yamaichi Y, Hiraga S. 2000. Dynamic organization of chromosomal DNA in Escherichia coli. Genes Dev 14: 212-223.

Osley MA, Newton A. 1974. Chromosomes segregration and development in Caulobacter crescentus. J Mol Biol 90: 359-370.

Pettijohn DE. 1982. Structure and properties of the bacterial nucleoid. Cell 30: 667-669.

Postow L, Hardy CD, Arsuaga J, Cozzarelli NR. 2004. Topological domain structure of the Escherichia coli chromosome. Genes Dev 18: 1766-1779.

Prentki P, Chandler M, Caro L. 1977. Replication of prophage P1 during the cell cycle of Escherichia coli. Mol Gen Genet 152: 71-76.

Ptacin JL, Nollmann M, Becker EC, Cozzarelli NR, Pogliano K, Bustamante C. 2008. Sequence-directed DNA export guides chromosome translocation during sporulation in Bacillus subtilis. Nat Struct Mol Biol 15: 485-493.

Ramamurthi KS, Losick R. 2009. Negative membrane curvature as a cue for subcellular localization of a bacterial protein. Proc Natl Acad Sci 106: 13541-13545.

Robinett CC, Straight A, Li G, Willhelm C, Sudlow G, Murray A, Belmont AS. 1996. In vivo localization of DNA sequences and visualization of large-scale chromatin organization using lac operator/repressor recognition. J Cell Biol 135: 1685-1700.

Robinow C, Kellenberger E. 1994. The bacterial nucleoid revisited. Microbiol Rev 58: 211-232.

Robinow CF. 1956. The chromatin bodies of bacteria. Bacteriol Rev 20: 207-242.

Ryter A. 1968. Association of the nucleus and the membrane of bacteria: A morphological study. Bacteriol Rev 32: 39-54.

Ryter A, Chang A. 1975. Localization of transcribing genes in the bacterial cell by means of high resolution autoradiography. J Mol Biol 98: 797-810.

Scheirer KE, Higgins NP. 2001. Transcription induces a supercoil domain barrier in bacteriophage Mu. Biochimie 83: $155-159$.

Schoeffler AJ, Berger JM. 2008. DNA topoisomerases: Harnessing and constraining energy to govern chromosome topology. Q Rev Biophys 41: 41-101.

Shebelut CW, Jensen RB, Gitai Z. 2009. Growth conditions regulate the requirements for Caulobacter chromosome segregation. J Bacteriol 191: 1097-1100.

Sinden RR, Pettijohn DE. 1981. Chromosomes in living Escherichia coli cells are segregated into domains of supercoiling. Proc Natl Acad Sci 78: 224-228.

Stonington OG, Pettijohn DE. 1971. The folded genome of Escherichia coli isolated in a protein-DNA-RNA complex. Proc Natl Acad Sci 68: 6-9.

Straight AF, Belmont AS, Robinett CC, Murray AW. 1996. GFP tagging of budding yeast chromosomes reveals that protein-protein interactions can mediate sister chromatid cohesion. Curr Biol 6: 1599-1608.

Sueoka N, Quinn WG. 1968. Membrane attachment of the chromosome replication origin in Bacillus subtilis. Cold Spring Harb Symp Quant Biol 33: 695-705.

Sullivan NL, Marquis KA, Rudner DZ. 2009. Recruitment of SMCby ParB-parS organizes the origin region and promotes efficient chromosome segregation. Cell 137: 697-707.

Surtees JA, Funnell BE. 2003. Plasmid and chromosome traffic control: How ParA and ParB drive partition. Curr Top Dev Biol 56: 145-180.

Teleman AA, Graumann PL, Lin DC, Grossman AD, Losick R. 1998. Chromosome arrangement within a bacterium. Curr Biol 8: 1102-1109.

Thanbichler M, Shapiro L. 2008. Getting organized-how bacterial cells move proteins and DNA. Nat Rev Microbiol 6: $28-40$.

Toro E, Hong SH, McAdams HH, Shapiro L. 2008. Caulobacter requires a dedicated mechanism to initiate chromosome segregation. Proc Natl Acad Sci 105: 15435-15440.

Van Helvoort JM, Woldringh CL. 1994. Nucleoid partitioning in Escherichia coli during steady-state growth and upon recovery from chloramphenicol treatment. $\mathrm{Mol}$ Microbiol 13: 577-583.

Viollier PH, Thanbichler M, McGrath PT, West L, Meewan M, McAdams HH, Shapiro L. 2004. Rapid and sequential movement of individual chromosomal loci to specific subcellular locations during bacterial DNA replication. Proc Natl Acad Sci 101: 9257-9262.

Wake RG, Errington J. 1995. Chromosome partitioning in bacteria. Annu Rev Genet 29: 41-67. 
Wang JC. 1971. Interaction between DNA and an Escherichia coli protein $\omega . \mathrm{J} \mathrm{Mol} \mathrm{Biol} \mathrm{55:} \mathrm{523-533.}$

Wang X, Liu X, Possoz C, Sherratt DJ. 2006. The two Escherichia coli chromosome arms locate to separate cell halves. Genes Dev 20: 1727-1731

Watson JD, Crick FH. 1953. Genetical implications of the structure of deoxyribonucleic acid. Nature 171: 964-967.

Webb CD, Teleman A, Gordon S, Straight A, Belmont A, Lin DC, Grossman AD, Wright A, Losick R. 1997. Bipolar localization of the replication origin regions of chromosomes in vegetative and sporulating cells of $B$. subtilis. Cell 88: 667-674.

Wheeler RT, Shapiro L. 1997. Bacterial chromosome segregation: Is there a mitotic apparatus? Cell 88: 577-579.

White MA, Eykelenboom JK, Lopez-Vernaza MA, Wilson E, Leach DR. 2008. Non-random segregation of sister chromosomes in Escherichia coli. Nature 455: 1248-1250.
High-order DNA Structure and Dynamics

Woldringh CL. 2002. The role of co-transcriptional translation and protein translocation (transertion) in bacterial chromosome segregation. Mol Microbiol 45: $17-29$.

Worcel A, Burgi E. 1972. On the structure of the folded chromosome of Escherichia coli. J Mol Biol 71: 127-147.

Wu LJ, Errington J. 1994. Bacillus subtilis spoIIIE protein required for DNA segregation during asymmetric cell division. Science 264: 572-575.

Wu LJ, Errington J. 2003. RacA and the Soj-Spo0J system combine to effect polar chromosome segregation in sporulating Bacillus subtilis. Mol Microbiol 49: 1463-1475.

Yamaichi Y, Niki H. 2004. migS, a cis-acting site that affects bipolar positioning of oriC on the Escherichia coli chromosome. EMBO J 23: 221-233.

Yamaichi Y, Fogel MA, Waldor MK. 2007. par genes and the pathology of chromosome loss in Vibrio cholerae. Proc Natl Acad Sci 104: 630-635. 


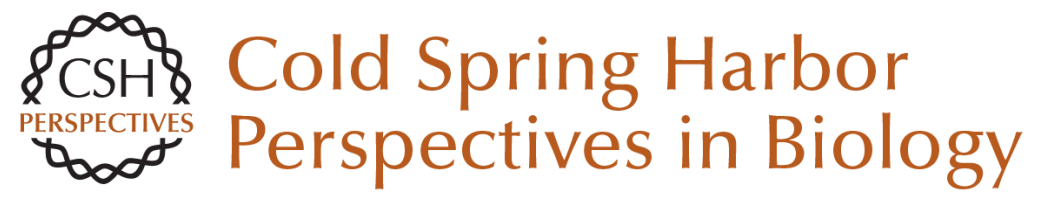

\section{Bacterial Chromosome Organization and Segregation}

Esteban Toro and Lucy Shapiro

Cold Spring Harb Perspect Biol 2010; doi: 10.1101/cshperspect.a000349 originally published online January 20, 2010

\section{Subject Collection Cell Biology of Bacteria}

\section{Electron Cryotomography}

Elitza I. Tocheva, Zhuo Li and Grant J. Jensen

Protein Subcellular Localization in Bacteria David Z. Rudner and Richard Losick

Poles Apart: Prokaryotic Polar Organelles and Their Spatial Regulation

Clare L. Kirkpatrick and Patrick H. Viollier

Myxobacteria, Polarity, and Multicellular

Morphogenesis

Dale Kaiser, Mark Robinson and Lee Kroos

Membrane-associated DNA Transport Machines

Briana Burton and David Dubnau

The Bacterial Cell Envelope

Thomas J. Silhavy, Daniel Kahne and Suzanne Walker

Cell Biology of Prokaryotic Organelles Dorothee Murat, Meghan Byrne and Arash Komeili

Bacterial Chromosome Organization and

\section{Segregation}

Esteban Toro and Lucy Shapiro
Cyanobacterial Heterocysts
Krithika Kumar, Rodrigo A. Mella-Herrera and
James W. Golden

Synchronization of Chromosome Dynamics and

Cell Division in Bacteria Martin Thanbichler

Automated Quantitative Live Cell Fluorescence

Microscopy

Michael Fero and Kit Pogliano

The Structure and Function of Bacterial Actin

Homologs Joshua W. Shaevitz and Zemer Gitai

\section{Biofilms}

Daniel López, Hera Vlamakis and Roberto Kolter

Bacterial Nanomachines: The Flagellum and Type

III Injectisome

Marc Erhardt, Keiichi Namba and Kelly T. Hughes

Single-Molecule and Superresolution Imaging in Live Bacteria Cells Julie S. Biteen and W.E. Moerner

For additional articles in this collection, see http://cshperspectives.cshlp.org/cgi/collection/

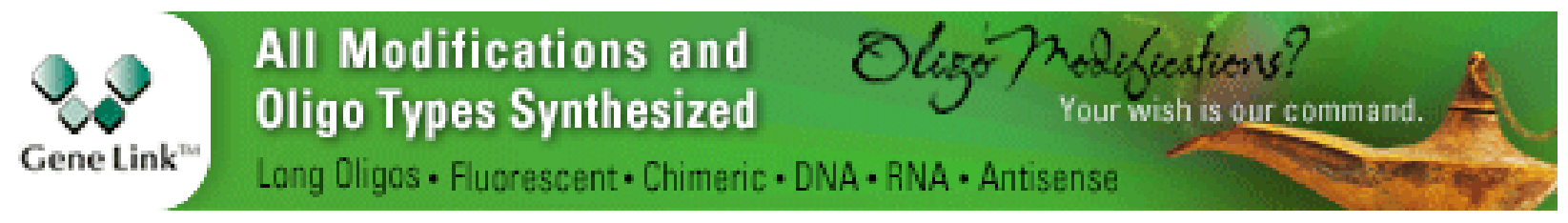

Copyright @ 2010 Cold Spring Harbor Laboratory Press; all rights reserved 